\title{
ANALISIS TERHADAP FAKTOR-FAKTOR YANG MEMPENGARUHI KINERJA UMKM FASHION DI JAKARTA, INDONESIA
}

\author{
Hendri Haryanti \\ Kementerian Agama, Indonesia \\ hendriharyanti.sag.@gmail.com
}

\begin{abstract}
Abstrak: Penelitian ini bertujuan untuk: menganalisis pengaruh digital capability terhadap kinerja dan keunggulan kompetitif; menganalisis pengaruh strategi inovasi terhadap keunggulan kompetitif dan kinerja; dan menganalisis pengaruh keunggulan kompetitif terhadap kinerja. Penelitian ini dilaksanakan di Jakarta dengan jumlah sampel sebanyak 245 pelaku UMKM Fashion yang memanfaatkan teknologi digital dalam kegiatan bisnis. Teknik analisis data menggunakan Structural Equation Model (SEM) with Partial Least Square (PLS). Hasil penelitian menunjukkan bahwa digital capability berpengaruh terhadap keunggulan kompetitif dan keunggulan kompetitif berpengaruh terhadap kinerja. Digital capability tidak berpengaruh langsung terhadap kinerja, hal ini bermakna keunggulan kompetitif menjadi variabel penting untuk memediasi digital capability terhadap kinerja UMKM Fashion. Strategi inovasi berpengaruh terhadap keunggulan kompetitif maupun terhadap kinjer UMKM.
\end{abstract}

Kata kunci: Digital Capability, Keunggulan Kompetitif, Strategi Inovasi, Kinerja UMKM

\section{ANALYSIS OF FACTORS AFFECTING THE PERFORMANCE OF MSME FASHION IN JAKARTA, INDONESIA}

\begin{abstract}
This study aims to: analyze the effect of digital capability on performance and competitive advantage, analyze the influence of innovation strategies on competitive advantage and performance, and analyze the impact of competitive advantage on performance. This research was conducted in Jakarta with a total sample of 245 fashion SMEs who utilize digital technology in business activities. The data analysis technique used the Structural Equation Model (SEM) with Partial Least Square (PLS). The results showed that digital capability affected competitive advantage and competitive advantage affected performance. Digital power does not directly affect performance; this means that competitive advantage is an important variable to mediate digital ability on the performance of MSME Fashion. The innovation strategy has an impact on the competitive advantage and the performance of the UMKM.
\end{abstract}

Keywords: Digital Capability, Competitive Advantage, Innovation Strategy, MSME Performance

\section{PENDAHULUAN}

Eksistensi UMKM terbukti mampu bertahan dan menjadi penggerak roda ekonomi. Sektor ini mampu menyerap tenaga kerja cukup besar, berkontribusi terhadap pertumbuhan sekaligus pemerataan ekonomi. Belum kokohnya fundamental perekonomian Indonesia saat ini, mendorong pemerintah untuk terus memberdayakan UMKM. Bagi UMKM hal ini perlu dilakukan untuk meningkatkan daya saing UMKM, utamanya agar dapat bersaing dengan produk-produk asing yang kian membanjiri sentra industri dan manufaktur di Indonesia (Sudaryanto et al., 2012).

Fashion dan kerajinan merupakan subsektor UMKM yang dominan dalam memberikan kontribusi ekonomi. Kedua jenis industri ini menjadi lokomotif dalam perkembangan industri kreatif nasional. Kontribusi fashion dan kerajinan jauh mengungguli kontribusi jenis industri kecil 
lainnya. Baik dalam nilai tambah, tenaga kerja, jumlah perusahaan, maupun nilai ekspornya (Riset et al., 2017). Oleh karena itu, penelitian ini memfokuskan kajian tentang UMKM Fashion.

Kemampuan UMKM dalam menghadapi terpaan arus persaingan global memang perlu mendapatkan perhatian serius agar tetap mampu bertahan demi kestabilan perekonomian. Strategi pengembangan UMKM untuk tetap bertahan dapat dilakukan dengan peningkatan daya saing dan pengembangan inovasi agar memiliki nilai dan mampu bertahan menghadapi globalisasi. Kinerja organisasi yang bagus pada akhirnya menghasilkan beberapa karya yang dinikmati kemudian menghasilkan keunggulan bersaing bagi perusahaan. Keunggulan bersaing yang telah diraih perusahaan seharusnya dapat terus dipertahankan karena dengan adanya keunggulan makin banyak kompetitor yang memperhatikan titik lemah perusahaaan, oleh karena itu perusahaan harus terus konsisten dalam menjaga keunggulannya (Sirivanh et al., 2014).

Keunggulan bersaing dapat juga dilihat melalui evaluasi pelanggan yang dapat diciptakan perusahaan melalui fasilitas-fasilitas pelayanan yang dapat menampung segala macam keluhan atau saran yang ditujukan konsumen untuk perusahaan demi perbaikan menuju yang lebih berkualitas. Pengaturan strategi yang baik menjadi kunci kesuksesan bagi perusahaan untuk dapat menjadi yang terdepan dengan adanya antisipasi dalam persaingan pasar (Tarabieh et al., 2015).

Salah satu pendekatan yang berfokus pada peningkatan keunggulan bersaing organisasi bisnis adalah Kapabilitas Digital (Soetjipto, 1999). Menurut Parida et al. (2016) kapabilitas digital adalah "a firm's ability to strategically use information and communication technology functions or applications in their business activities, such as use of e-mails, website, e-commerce, web conferencing, intranet, extranet and other similar tools". Berdasarkan defenisi Clegg et al. (2002) tersebut, kapabilitas digital merupakan kemampuan perusahaan untuk menggunakan fungsi dan aplikasi TIK dalam aktifitas bisnis, seperti menggunakan e-mail, website, e-commerce, web conference, intranet, ekstranet dan aplikasi TIK lainnya. Dengan demikian, kapabilitas TIK diperlukan agar perusahaan mampu menyesuaikan, mengintegrasikan, mengonfigurasi ulang dan menciptakan kembali kompetensi internal dan eksternal sehingga dapat meraih keunggulan kompetitif dalam lingkungan bisnis yang selalu berubah (Soetjipto, 1999).

Pemanfaatan media digital sebagai kapabilitas perusahaan pada usaha kecil di Indonesia menunjukan pertumbuhan yang tinggi. Euromonitor Internasional mencatat bahwa penjualan online Indonesia lebih tinggi dari Thailand dan Singapura. Pasar e-commerce Indonesia diyakini berpeluang untuk tumbuh semakin besar. Hal tersebut didukung dengan jumlah penduduk dan tingkat produk domestik bruto (PDB) terbesar di ASEAN. Statista International mencatat rata-rata pertumbuhan tahunan penjualan online Indonesia selama 2014-2020 terus tumbuh. Teknologi akses jaringan pada transaksi online yang digunakan pada transaksi online untuk pembeli perorangan menunjukan bahwa mobile broadband wireless (3G, LTE/4G) paling banyak digunakan. Hal tersebut berarti perkembangan teknologi mobile phone berpengaruh pada dinamika bisnis. Kementerian Koperasi dan UMKM mencatat bahwa pelaku UMKM yang sudah memanfaatkan teknologi digital seperti e-commerce sudah mencapai 3,79 juta UMKM (Zultaqawa et al., 2019).

Setelah melakukan berbagai kajian bahwa untuk bisa bertahan maka UMKM harus memiliki kinerja yang tinggi serta keunggulan dalam bersaing. Maka penelitian ini menetapkan fokus kajian dengan melakukan analisis terhadap variabel yang diduga menjadi problem utama UMKM yakni kapabilitas digital (Soetjipto, 1999). Bersamaan dengan variabel kapabilitas digital penelitian ini juga menganalisis variabel keunggulan kompetitive sebagai variabel yang berpengaruh terhadap kinerja UMKM (Majeed, 2011; Rahim et al., 2016). 


\section{METODE}

Penelitian ini merupakan penelitian eksplanatif asosiatif dengan pendekatan kuantitatif. Objek penelitian adalah UMKM fashion di berbagai wilayah di Jabodetabek dengan kriteria: 1) memanfaatkan teknologi digital dalam kegiatan bisnis dan 2) usaha sudah berjalan minimal 2 (dua) tahun. Analisis menggunakan teknik Structural Equation Model (SEM) with Partial Least Square (PLS). Jumlah sampel sebanyak 200 pelaku usaha UMKM. Sebagaimana anjuran Suharjo dan Suwarno (2002) bahwa jumlah sampel yang memberikan hasil yang cukup stabil berkisar antara 100 responden sampai dengan 200 responden.

\section{HASIL DAN PEMBAHASAN}

Profile pelaku usaha UMKM berdasarkan jenis kelamin menunjukkan bahwa perempuan lebih dominan (61.15\%) daripada laki-laki sebanyak (22.75\%) dari total 200 responden. Distribusi responden berdasarkan pendidikan terakhir dibagi menjadi 5 (lima) kategori yaitu SMA atau di bawah Diploma (D3) sebesar 3.04\%, Diploma (D3) sebanyak 3.91\%, Sarjana (S1) 90.87\%, Pasca Sarjana (S2) $1.74 \%$ dan Doktor (S3) sebanyak 0.43\%. Berdasarkan kriteria UU No. 20 Tahun 2008 tentang kriteria UMKM maka distribusi responden yang termasuk kriteria usaha mikro sebanyak $87.60 \%$, usaha kecil sebanyak $7.44 \%$ dan usaha menengah sebanyak $4.96 \%$.

Berikutnya adalah analisis dengan menggunakan SEM - PLS. Analisis SEM - PLS dilakukan dengan tiga tahap yakni analisis outer model, analisis inner model, dan pengujian hipotesis. Menurut Ghozali (2006), untuk uji reliabilitas konstruk diukur dengan composite reliability dan cronbach's alpha. Konstruk dinyatakan reliabel jika memiliki nilai composite reliability di atas 0,70dan cronbach's alpha di atas 0,60. Sedangkan nilai average variance extracted (AVE) yang memadai untuk mengukur validitas adalah sebesar 0,5 .

\begin{tabular}{|c|c|c|c|c|c|}
\hline & $\begin{array}{l}\text { Cut-off } \\
\text { Value }\end{array}$ & $\begin{array}{c}\text { Digit_- } \\
\text { Capabil }\end{array}$ & $\begin{array}{c}\text { Comp_Ad } \\
\text { vantage }\end{array}$ & $\begin{array}{c}\text { Performan } \\
\text { ce_SME }\end{array}$ & Keterangan \\
\hline $\begin{array}{l}\text { Cronbach's } \\
\text { Alpha }\end{array}$ & $>0.6$ & 0,823 & 0,823 & 0,819 & Semua \\
\hline $\begin{array}{l}\text { Composite } \\
\text { Reliability }\end{array}$ & $>0.7$ & 0.763 & 0.840 & 0.849 & $\begin{array}{l}\text { aspek } \\
\text { Usaha }\end{array}$ \\
\hline $\begin{array}{l}\text { Average } \\
\text { Variance } \\
\text { Extracted } \\
(A V E)\end{array}$ & $>0.5$ & 0.729 & 0,623 & 0,661 & $\begin{array}{c}\text { kecil } \\
\text { fashion } \\
\text { memenuhi } \\
\text { standar }\end{array}$ \\
\hline
\end{tabular}

Sumber: Data Diolah (2019)

Berdasarkan kriteria tabel 1 maka output olah data menunjukkan hasil semua kriteria outer model terpenuhi sehingga dapat disimpulkan bahwa data penelitian memiliki validitas dan realibilitas yang baik, oleh karena itu bisa dilanjutkan ke analisis inner model. Evaluasi inner model dapat dilihat dari beberapa indikator yang meliputi; koefisien determinasi $\left(\mathrm{R}^{2}\right)$; Predictive Relevance $\left(\mathrm{Q}^{2}\right)$; Goodness of Fit Index $(\mathrm{GoF})$. Berikut disajikan perhitugan untuk masing-masing indikator. 
Tabel 2. Nilai $\mathrm{R}^{2}$

\begin{tabular}{lcc}
\hline & $\boldsymbol{R}$ Square & $\boldsymbol{R}$ Square Adjusted \\
\hline Digital Capability & 0,768 & 0,737 \\
Keunggulan Kompetitif & 0,786 & 0,743 \\
Kinerja & 0,773 & 0,741 \\
\hline \multicolumn{2}{l}{ Sumber: Data Diolah (2019) } &
\end{tabular}

Menurut Schunk (2012), nilai R square sebesar 0.67 (kuat), 0.33 (moderat) dan dibawah 0.19 (lemah). Maka model penelitian ini terkategori memiliki hubungan yang kuat diantara variabelvariabel yang dianalisis. Dalam penelitian ini terdapat dua variabel endogen yakni keunggulan kompetitif dan kinerja serta satu variabel eksogen. Berdasarkan nilai $r$ square dan adjusted $r$ square, maka terdapat hubungan yang kuat antara variable eksogen baik secara mandiri maupun secara bersama-sama. Untuk menghitung Q2 dapat digunakan rumus:

$$
\begin{aligned}
& \mathrm{Q}^{2}=1-\left(1-\mathrm{R} 1^{2}\right)\left(1-\mathrm{R} 2^{2}\right) \ldots . .\left(1-\mathrm{Rn}^{2}\right) \\
& \mathrm{Q}^{2}=1-(1-0,768)(1-0,786)(1-0,773) \\
& \mathrm{Q}^{2}=0,989
\end{aligned}
$$

Menurut Schunk (2012), apabila nilai yang didapatkan 0.02 maka model memiliki kapabilitas prediksi yang kecil. Jika nilai yag didapatkan 0.15 maka model memiliki kapabilitas prediksi yang kecil sedang. Dan jika nilai yang didapatkan 0.35 maka model memiliki kapabilitas prediksi yang besar. Perhitungan terhadap nilai $\mathrm{Q}^{2}$ didapatkan hasil sebesar 0.989 maka model memiliki kapabilitas prediksi yang besar. Nilai GoF pada SEM with PLS dihitung secara manual (Tenenhaus (2004) dengan rumus:

$$
\begin{aligned}
& \mathrm{GoF}=\sqrt{A V E^{2} \times \mathrm{R}^{2}} \\
& \mathrm{GoF}=0.4
\end{aligned}
$$

Menurut Tenenhaus et al. (2004), nilai GoF small $=0,1$, GoF medium $=0,25$ dan GoF besar $=0,38$. Berdasarkan perhitungan nilai GoF maka dapat diketahui bahwa model memiliki nilai GoF yang besar sehingga model yang di bentuk mewakili fenomena nyata yang sesungguhnya.Langkah selanjutnya adalah uji hipotesis penelitian. Untuk melakukan uji hipotesis di SEM PLS dilakukan dengan proses bootstrapping yang menghasilkan nilai T-hitung. Jika nilai thitung lebih besar dari t-statistik dengan tingkat kepercayaan 95\% ( $>1.96)$ maka hipotesis signifikan. Sedangkan untuk mengetahui seberapa besar pengaruh diantara varabel-variabel penelitian maka dilihat nilai loading factor original sample.

Tabel 3. Path Coefficients (Mean, STDEV, t-Value)

\begin{tabular}{lccccc}
\hline \multicolumn{1}{c}{ Hipotesis } & $\begin{array}{c}\text { Original } \\
\text { Sample (O) }\end{array}$ & $\begin{array}{c}\text { Sample } \\
\text { Mean (M) }\end{array}$ & $\begin{array}{c}\text { Standard Deviation } \\
\text { (STDEV) }\end{array}$ & $\begin{array}{c}\text { T Statistics } \\
(|\mathbf{O} / \mathbf{S T D E V}|)\end{array}$ & P Values \\
\hline $\begin{array}{l}\text { Digital_Capability -> } \\
\text { SME Performance }\end{array}$ & 0,154 & 0,156 & 0,106 & 1,461 & 0.144 \\
$\begin{array}{l}\text { Digital_Capability-> } \\
\text { Competitive Advantage }\end{array}$ & 0,438 & 0,465 & 0,075 & 5,822 & 0,000 \\
$\begin{array}{l}\text { Competitive } \\
\text { Advantage-> SME }\end{array}$ & 0,470 & 0,488 & 0,086 & 5,445 & 0,000 \\
\begin{tabular}{l} 
Performance \\
\hline
\end{tabular} & & & & & \\
\hline
\end{tabular}

Sumber: Data Diolah (2019) 
Berdasarkan tabel 3. output path coefficients (Mean, STDEV, t-value) maka diperoleh bahwa sebanyak 2 hipotesis memiliki nilai $\mathrm{t}$ value diatas 1,96 dan satu hipotesis memiliki t value di bawah 1,96. Artinya dari tiga hipotesis penelitian, sebanyak 2 hipotesis terbukti memiliki pengaruh positif dan signifikan. Sedangkan satu hipotesis tidak signifikan. Kesimpulan tersebut dapat diringkas dalam tabel tersebut:

Tabel 4. Rangkuman Hasil Uji Hipotesis Penelitian

\begin{tabular}{lllc}
\hline \multicolumn{3}{c}{ Hipotesis } & Hasil \\
\hline $\mathrm{H}_{1}$ & $\begin{array}{l}\text { Kapabilitas } \\
\text { Performance }\end{array}$ & Digitalberpengaruh terhadap SME & Ditolak \\
$\mathrm{H}_{2}$ & $\begin{array}{l}\text { Kapabilitas } \\
\text { Competitive Advantage }\end{array}$ & Digitalberpengaruh terhadap & Diterima \\
$\mathrm{H}_{3}$ & $\begin{array}{l}\text { Competitive Advantage berpengaruh terhadapSME } \\
\text { Performance }\end{array}$ & Diterima \\
\hline
\end{tabular}

Sumber: Data Diolah (2019)

Berdasarkan hasil running dapat diketahui bahwa variabel digital capability memiliki pengaruh yang tidak signifikan terhadap competitive advantage. Hal ini berbeda dengan hasil penelitian sebelumnya yang dilakukan oleh Clarismary (2015) menunjukkan bahwa teknologi informasi berpengaruh positif terhadap kinerja organisasi. Hal ini dapat diterima sebab yang menjadi titik tekan dalam penelitian ini adalah kemampuan digital (digital capability) bukan teknologi informasinya.

Kemampuan yang dibutuhkan untuk berkembang di zaman ini adalah ketika mampu mendominasi bentuk informasi dan komunikasi digital (HELEN BEETHAM, 2013). Teknologi informasi berguna untuk mengurangi biaya dalam kegiatan bisnis, terutama bagi UMKM untuk mengalokasikan dan menyimpan anggaran mereka untuk penggunaan lainnya (Muafil, 2014).

Teknologi informasi yang baik adalah teknologi yang mampu membangun informasi yang berguna dalam membangun keunggulan bersaing perusahaan. Hasil penelitian (Cakmak \& Tas, 2012) menunjukkan bahwa teknologi informasi berpengaruh positif terhadap keunggulan bersaing. Pesaing menjadikan perusahaan menggunakan media digital untuk melakukan penetrasi pasar kepada pasar kompetitor usaha dengan cara diferensiasi hasil usaha (Cakmak \& Tas, 2012). Hasil penelitian Clarismary (2015) menyatakan bahwa teknologi informasi berpengaruh positif terhadap kinerja organisasi.

Media digital memberikan kemudahan bagi konsumen atau calon konsumen untuk dapat mengakses informasi dimanapun dan kapanpun, keuntungan lain juga didapat ketika perusahaan dapat memantau apa saja perubahan atau strategi yang dilakukan pelaku usaha sejenis kepada perusahaanya (Chukwunonso et al., 2011). Selain dapat digunakan perusahaan untuk melakukan pemantauan kegiatan kompetitor, media digital juga dapat berfungsi sebagai tambahan informasi kepada perusahaan mengenai hal baik apa saja yang belum dilakukan perusahaan untuk menambah daya saingnya di pasar. Hal ini biasanya dilakukan oleh perusahaan yang berada di negara berkembang dimana mereka memantau inovasi yang dilakukan oleh perusahaan di negara maju dalam menambah nilai jual akan hasil produknya (Ling et al., 2013). Inti dari fungsi media digital adalah terciptanya efisiensi untuk mengurangi pemborosan yang dilakukan oleh perusahaan (Fernandez, 2013). 
Terdapat perbedanaan makna antara kapabilitas TIK dengan TIK itu sendiri. Soetjipto (1999) mendefenisikan Kapabilitas TIK adalah kemampuan yang dimiliki oleh pelaku usaha untuk memanfaatkan media digital/teknologi informasi untuk menunjang jalannya usaha.Teknologi Informasi adalah seperangkat teknologi yang digunakan oleh suatu organisasi untuk menghasilkan, proses, dan menyebarkan informasi dalam setiap bentuk. Oleh karena itu, teknologi informasi menyediakan dukungan untuk operasional perusahaan (Sirivanh et al., 2014)

Hasil penelitian ini sejalan dengan publikasi OECD tahun 2014 yang menyatakan bahwa salah satu kelemahan dari UMKM adalah terbatasnya kapabilitas dan agresifitas dari pemilik maupun pekerja UMKM meningkatkan kinerja usaha dengan memanfaatkan media digital. Terdapat beberapa faktor yang dapat menghambat penggunaan internet di UMKM, diantaranya adalah ketidak sesuaian proses bisnis, keterbatasan pengetahuan dalam hal penggunaan internet, keterbatasan kemampuan managerial dalam penggunaan internet, keterbatasan jumlah komputer dan koneksi internet, kurangnya kepercayaan dan keamanan dalam pemanfaatan internet, serta besarnya biaya pengembangan dan pemeliharaan komputer.

Kinerja organisasi yang superior mencerminkan keunggulan kompetitif perusahaan. Keunggulan kompetitif adalah kemampuan untuk memenangkan persaingan pasar melalui cara yang berbeda yang tidak dapat dilakukan oleh pesaing (Porter \& Porter, 1989). Hasil dari beberapa penelitian sebelumnya menunjukkan bahwa keunggulan kompetitif mempengaruhi kinerja organisasi (Majeed, 2011; Rahim et al., 2016). Keunggulan kompetitif akan diperoleh jika sebuah perusahaan dapat menggunakan sumber daya unggulan mereka, termasuk keterampilan untuk mencapai nilai pelanggan yang superior dan biaya yang relatif rendah (Porter \& Porter, 1989).

Berdasarkan eksplorasi terhadap konsep daya saing maka penelitian ini mensintesis beberapa dimensi tentang keunggulan bersaing yakni diferensiasi (Tarabieh et al., 2015), pengetahuan teknis mutakhir, merek dagang (Sirivanh et al., 2014) dan unik. Unik didefenisikan sebagai suatu nilai yang membedakan produk dengan produk yang lain. Agar UMKM memiliki keunggulan bersaing maka harus menghasilkan produk yang bersifat unik.

Kinerja Perusahaan adalah suatu tampilan keadaan secara utuh suatu perusahaan selama periode waktu tertentu, yang merupakan hasil kegiatan operasional perusahaan dalam memanfaatkan sumber-sumber daya yang dimiliki (Laforet, 2008). Kinerja organisasi harus diukur secara subjektif bila memungkinkan untuk memeriksa pengaruh bahwa orientasi pelanggan dan layanan tambahan memiliki lebih dari itu (Tarabieh et al., 2015). Pengukuran kinerja sendiri sebagai proses mengukur efisiensi dan efektivitas tindakan. Pengukuran kinerja juga dapat didefinisikan mengukur input, output,atau tingkat aktivitas dari suatu peristiwa atau proses (Chukwunonso et al., 2011).

Supartha (2016) memanfaatkan konsep Total Quality Management (TQM) untuk mengukur kinerja UMKM. Douglas \& Judge (2001) mengoperasionalkan TQM sebagai konstruksi unidimensional. Berdasarkan tinjauan literatur, faktor-faktor kritis TQM yang paling umum digunakan yang mempengaruhi kinerja bisnis adalah kepemimpinan manajemen (management leadership), pelatihan (training), fokus pelanggan (customer focus), perbaikan terus-menerus (continuous improvement), perencanaan strategis dan manajemen proses (management process).

Berdasarkan hasil running terbukti bahwa variabel digital capability memiliki pengaruh signifikan terhadap competitive advantage.Hasil penelitian ini sesuai dengan penelitian yang telah dilakukan oleh (Cakmak \& Tas, 2012), yang menunjukkan bahwa digital capability berpengaruh positif terhadap keunggulan bersaing. Digital capability akan mempengaruhi keunggulan bersaing UMKM, sebab dengan adanya kemampuan digital yang memadai akan dapat meningkatkan keunggulan bersaing. Digital capability adalah kemampuan yang dimiliki oleh pelaku usaha untuk memanfaatkan media digital/teknologi informasi untuk menunjang jalannya usaha.Teknologi Informasi adalah seperangkat teknologi yang digunakan oleh suatu organisasi untuk 
menghasilkan, proses, dan menyebarkan informasi dalam setiap bentuk.Oleh karena itu, teknologi informasi menyediakan dukungan untuk operasional perusahaan.Teknologi informasi berguna untuk mengurangi biaya dalam kegiatan bisnis, terutama bagi UMKM yang membutuhkan alokasi anggaran untuk penggunaan lainnya (Muafil, 2014).

Bisa difahami digital capability berpengaruh terhadap competitive advantage dan tidak berpengaruh terhadap SME Performance. Sebab menurut Clarismary (2015), dimensi ICT proficiency merupakan dimensi yang mampu berpengaruh secara langsung terhadap kinerja perusahaan, justru memiliki bobot yang kecil dibanding dimensi lain. ICT proficiency didefinisikan sebagai kecakapan menilai secara kritis manfaat/ kendala penerapan dan pendekatan TIK; merancang dan menerapkan solusi TIK untuk pulih dari kegagalan dan maintenance target.Self actualizing didefenisikan sebagai upaya membangun dan memelihara profil digital; mengembangkan gaya dan nilai pribadi dalam partisipasi digital; menyusun materi pribadi di jaringan digital. Learning didefenisikan sebagai kemampuan untuk mengidentifikasi dan berpartisipasi dalam pembelajaran digital; dan atau berpartisipasi dalam belajar berhubunga melalui media digital. Participating didefenisikan sebagai partisipasi dalam kehidupan social, budaya dan bisnis dengan menggunakan layanan dan forum digital.

Variabel competitive advantage memiliki pengaruh signifikan terhadap SME performance.Kinerja organisasi yang superior mencerminkan keunggulan kompetitif perusahaan. Keunggulan kompetitif adalah kemampuan untuk memenangkan persaingan pasar melalui cara yang berbeda yang tidak dapat dilakukan oleh pesaing (Porter \& Porter, 1989). Hasil dari beberapa penelitian sebelumnya menunjukkan bahwa keunggulan kompetitif mempengaruhi kinerja organisasi (Majeed, 2011; Rahim et al., 2016).

Mulja (2001) menyatakan bahwa konsep keunggulan kompetitif harus diperhatikan oleh perusahaan atau organisasi yang memproduksi barang dan jasa untuk kelangsungan hidupnya dan keuntungannya. Kinerja bisnis UMKMakan ditingkatkan oleh keunggulan kompetitif UMKM tersebut melalui pertumbuhan laba, pertumbuhan penjualan dan pertumbuhan pelanggan. Menurut hasil (Chan et al., 2004), keunggulan kompetitif berpengaruh positif terhadap kinerja perusahaan. Beberapa indikator harus diciptakan untuk mengukur keuntungan (Dessler, 1997) termasuk loyalitas pelanggan, pengembangan teknologi dan pengembangan produk. Pengukuran pengembangan penjualan, pengembangan pelanggan, pengembangan laba dan pengembangan modal kerja merupakan indikator performansi bisnis UMKM. Penelitian ini menemukan dua dimensi kinerja UMKM yang dominan yakni fokus pelanggan (customer focus) dan perbaikan terusmenerus (continuous improvement).

\section{SIMPULAN}

Penelitian ini telah membuktikan pengaruh variabel digital capability terhadap keungulan bersaing dan kinerja UMKM Fashion di Jakarta.Hasil penelitian menunjukkan bahwa di Indonesia digital capability tidak berpengaruh terhadap kinerja UMKM, hasil ini sejalan dengan publikasi OECD (2014). Namun menurut publikasi yang sama digital capability berpengaruh signifikan terhadap kinerja pada usaha dengan skala besar. Ada banyak faktor yang menyebabkan digital capability tidak berpengaruh signifikan terhadap kinerja UMKM, diantaranya yaitu ketidaksesuaian proses bisnis, keterbatasan pengetahuan manajerial dalam hal penggunaan internet, keterbatasan jumlah komputer dan koneksi internet, kurangnya kepercayaan dan keamanan dalam pemanfaatan internet serta besarnya biasa pengembangan dan pemeliharaan komputer. Penelitian ini membuktikan bahwa digital capability di bentuk oleh creative, critical use, ICT Proficiency, learning, participating, dan self actualising. Dari enam dimensi tersebut dimensi utama adalah self actualitasing. Hal ini terbukti tidak memberikan pengaruh terhadap kinerja UMKM namun berpengaruh terhadap keunggulan bersaing. 
Penelitian ini juga membuktikan bahwa keunggulan bersaing berpengaruh terhadap kinerja melalui dimensi yang berbeda dengan penelitian-penelitian sebelumnya. Dimensi yang diajukan dalam penelitian ini adalah diferensiasi, merek, pengetahuan dan unik. Hal ini semakin menegaskan teori bahwa keunggulan bersaing akan senantiasa meningkatkan kinerja bisnis meski dimensi yang dipakai berbeda. Kinerja UMKM pada penelitian ini terdiri dari management leadership, training, customer focus), continuous improvement, management process. Dimensi utama adalah perbaikan terus menerus, hal ini sejalan dengan variabel inovasi strategi yang agresif. Manajemen leadership dan manajemen process terbukti bukan dimensi yang dominan pada variabel kinerja UMKM.

Pelaku UMKM masih perlu meningkatkan kemampuan digital terutama meningkatkan ICT Proficiency sehingga pelaku UMKM dapat lebih efisien dan efektif dalam mengoperasionalkan usaha, memperoleh informasi serta dapat menggunakanya sebagai media promosi atau pengenalan diri secara luas kepada masyarakat agar dapat secara langsung berpengaruh tehadap kinerja usahanya.

\section{DAFTAR PUSTAKA}

Cakmak, P. I., \& Tas, E. (2012). The use of information technology on gaining competitive advantage in Turkish contractor firms. World Applied Sciences Journal, 18(2), 274-285. https://doi.org/10.5829/idosi.wasj.2012.18.02.744

Chan, L. L. M., Shaffer, M. A., \& Snape, E. (2004). In search of sustained competitive advantage: The impact of organizational culture, competitive strategy and human resource management practices on firm performance. International Journal of Human Resource Management, 15(1), 1735. https://doi.org/10.1080/0958519032000157320

Chukwunonso, F., Omoju, J. O., Ikani, D., \& Ribadu, M. B. (2011). Management of Information Technology for Competitive Advantage : a Savvy Case Study. May 2014.

Clarismary, O. . (2015). "Change in Information Technology and Organizational Perfomance: a study of Consolidated Hallmark",. International Journal of Management and Commerce Innovations, 3(1), 579-587.

Clegg, C., Unsworth, K., Epitropaki, O., \& Parker, G. (2002). Implicating trust in the innovation process. Journal of Occupational and Organizational Psychology, 75(4), 409-422. https://doi.org/10.1348/096317902321119574

Dessler, G. (1997). Manajemen sumber daya manusia (7th ed.).

Douglas, T. J., \& Judge, W. (2001). TQM Implementation and Competitive Advantage Structural Control and Exploration. Academy of Management Journal, 44(1), 158-189.

Fernandez, R. (2013). Teachers' Competence And Learners' Performance In The Alternative Learning System Towards An Enriched Instructional Program. International Journal of Information Technology and Business Management, 22(1), 34. https://doi.org/10.13140/RG.2.2.26402.15042

Ghozali, I. (2006). Aplikasi Analisis Multivariate dengan Program SPSS. Badan Penerbit Universitas Diponegoro.

Helen Beetham, R. S. (2013). Rethinking Pedagogy for a Digital Age. Routledge. https://doi.org/https://doi.org/10.4324/9780203078952

Laforet, S. (2008). Size, strategic, and market orientation affects on innovation. Journal of Business Research, 61(7), 753-764. https://doi.org/10.1016/j.jbusres.2007.08.002

Ling, L. S., Tee, O. P., \& Eze, U. C. (2013). The Effects of Information Technology Applications on Collaborating Capability in Achieving Organisational Competitive Advantages in 
Malaysia. International Journal of Business and Management, 8(13), 1-14. https://doi.org/10.5539/ijbm.v8n13p1

Majeed, S. (2011). The Impact of Competitive Advantage on Organizational Performance. European Journal of Business and Management, 3(4), 191-197.

Muafil. (2014). Organizational Performance and Competitive Advantage Determinants of Creative SMEs. European Journal of Economics and Management, CXVI(February 2001), 1-53.

Mulja, R. (2001). Analisa Pengaruh Strategi Pelayanan Prima dan Fasilitas Terhadap Kepuasan Nasabah Pada PT. Bank Negara Indonesia (Persero) TBK Kantor Cabang Semarang.

Parida, V., Oghazi, P., \& Cedergren, S. (2016). A study of how ICT capabilities can influence dynamic capabilities. Journal of Enterprise Information Management, 29(2), 179-201. https://doi.org/10.1108/JEIM-07-2012-0039

Porter, M. E., \& Porter, M. E. (1989). Strategy. Harvard Business Review, 234-235.

Rahim, S. H. A., Rashid, R. A., \& Hamed, A. B. (2016). Factor Analysis of Islamic Financial Literacy and Its Determinants : A Pilot Study. International Soft Science Conference, 413-418.

Riset, K., Dan, T., \& Tinggi, P. (2017). Pedoman Operasional Baku.

Schunk, D. H. (2012). LEARNING THEORIES An Educational Perspective. In E. Setyowati (Ed.), Pustaka Pelajar (keenam). Pustaka Pelajar.

Sirivanh, T., Sukkabot, S., \& Sateeraroj, M. (2014). The Effect of Entrepreneurial Orientation and Competitive Advantage on SMEs ' Growth: A Structural Equation Modeling Study. International Journal of Business and Social Science, 5(6), 189-195.

Soetjipto, R. K. (1999). Profesi keguruan. Rineka Cipta.

Sudaryanto, Ragimun, \& Wijayanti, R. R. (2012). Strategi Pemberdayaan UMKM Menghadapi Pasar Bebas Asean. Jurnal Ekonomi Akuntansi danManajemen. 1-32.

Supartha, W. G. (2016). PENGARUH GAYA KEPEMIMPINAN DAN MOTIVASI KERJA TERHADAP KINERJA GURU. Jurnal Ekonomi Dan Bisnis, 3, 429-454.

Tarabieh, S. M. Z. A., Ahmad, Z. A., \& Siron, R. (2015). The Synergistic Impact of Customer Orientation and Supplementary Services on Competitive Advantage and Organizational Performance (Pilot Survey). International Review of Management and Business Research, 4(2), 484-498.

Tenenhaus, M., Amato, S., \& Vinzi, E. V. (2004). A Global Goodness-of-fit Index for PLS Structural Equation Modelling. The XLII SIS Scientific Meeting, 739-742.

Zultaqawa, Z., Alexandri, M. B., Rizal, M., Kostini, N., \& Aulia, M. D. (2019). Pengaruh Aksesibilitas, IT, dan Aksi Kompetitif Pada Usaha Mikro Kecil dan Menengah. Responsive, 2(1), 25. https://doi.org/10.24198/responsive.v2i1.23020 